\title{
Literatura e história em El señor presidente, de Miguel Ángel Asturias: registro de seu tempo
}

\author{
Literature and history in El señor president of Miguel Ángel Asturias: your time record
}

Margarete Hülsendeger ${ }^{1}$, Regina Kohlrausch²

Doutoranda em Teoria da Literatura/PUCRS. E-mail: margacenteno@gmail.com

Doutora em Letras, área de concentração Teoria da Literatura; Professora Titular da Faculdade de Letras da PUCRS (Graduação

E-mail: regina.kohlrausch@pucrs.br
RESUMO: 0 guatemalteco Miguel Ángel Asturias (1899-1974), escritor, diplomata e Prêmio Nobel de Literatura (1967) foi um dos grandes escritores latino-americanos, junto com Gabriel García Márquez e Mario Vargas Llosa. Entre suas várias obras destaca-se El señor presidente (1946), o romance que lhe trouxe fama internacional e no qual traça, de forma caricatural e grotesca, o retrato de um típico ditador latino-americano e de seu governo baseado no terror, na maldade e na morte. Nesse contexto, onde predomina o medo e a crueldade, aparecem duas mulheres - Camila Canales e Niña Fedina - que, unidas pela tragédia, terão de fazer frente a esse jogo de poder entre o bem e o mal. Na análise da trajetória dessas duas personagens se percebe a construção de uma narrativa hibrida, porque "incorpora la historia en la literatura", que coloca a mostra a luta travada entre as forças da luz - o povo oprimido do qual fazem parte as mulheres, muitas vezes ignoradas - e a das trevas - o ditador e todos que, por medo ou ambição, compactuam com ele -, segundo os mitos latino-americanos. Neste trabalho, ao destacar essas duas personagens, objetiva-se mostrar, como sinalizou Pesavento (2006), que a literatura e a história "guardam com a realidade distintos níveis de aproximação", e que a literatura pode servir de fonte para a história, enquanto "registro e impressão da vida", porque é um "inegável registro de seu tempo".

PALAVRAS-CHAVE: Miguel Ángel Asturias; Literatura Latino-americana; Literatura e história.

ABSTRACT: The Guatemalan Miguel Angel Asturias (1899-1974), writer, diplomat and Nobel Prize for Literature (1967) was one of the greatest Latin American writers, along with Gabriel Garcia Marquez and Mario Vargas Llosa. Among his many works, the most renowned is El señor presidente (1946), a novel that brought him international fame and through which he represents, in a very bizarre way, the portrait of a typical Latin American dictator and his government based on terror, evil, and death. In this context, dominated by fear and cruelty, two women appear - Camila Canales and Nina Fedina - who, united by the tragedy, will have to cope with this power play between good and evil. In the analysis of the female trajectory, one can observe the construction of a hybrid narrative since it incorporates "la historia en la literature," which shows the struggle between the forces of light and the forces of darkness. According to the Latin American myths, the former represented the oppressed, including women, often ignored; the latter, the dictator and all those people who condoned him by fear or ambition. By highlighting the role of these two female characters, this work aims to show that literature and history reflect reality through different levels of identity (Pesavento, 2006), and that literature can serve as a source for history, regarding "registration and impression of life", since it is "an undeniable record of its time."

KEYWORDS: Miguel Angel Asturias; Latin American Literature; Literature and history. 
O: discursos literário e histórico, conforme Pesavento, "são formas diferentes de dizer o real. Ambos são representações construídas sobre o mundo e que traduzem sentidos e significados inscritos no tempo" (PESAVENTO, 2006, p. 7). Entretanto, afirma a estudiosa, "as narrativas histórica e literária guardam com a realidade distintos níveis de aproximação" (PESAVENTO, 2006, p. 7). Conforme explica, seguindo a linha aristotélica, enquanto os historiadores frequentam arquivos e arrecadam fontes, valendo-se de um método de análise e pesquisa, na busca pela proximidade com o real acontecido, "os escritores de literatura não tem esse compromisso com o resgate das marcas de veracidade que funcionam como provas de que algo deva ter existido" (PESAVENTO, 2006, p. 7). Esclarece, ainda, que o texto literário, em princípio, "precisa, ele também, ser convincente e articulado, estabelecendo uma coerência e dando impressão de verdade. Escritores de ficção também contextualizam seus personagens, ambientes e acontecimentos para que recebam aval do público leitor" (PESAVENTO, 2006, p. 7).

Ampliando a especificidade do texto ficcional, para validar seu argumento de que a literatura pode ser fonte para a história, Pesavento diz que "o texto de ficção literária é enriquecido pela propriedade de ser o campo por excelência da metáfora" (PESAVENTO, 2006, p. 7) e que "essa figura de linguagem, pela qual se fala de coisas que apontam para outras coisas, é uma forma de interpretação do mundo que se revela cifrada" (PESAVENTO, 2006, p. 7). Por isso, a literatura é, ao mesmo tempo, uma fonte privilegiada para o historiador porque lhe dará "acesso especial ao imaginário" (PESAVENTO, 2006, p. 7) e uma fonte especialíssima porque lhe "dá a ver, por vezes de forma cifrada, as imagens sensíveis do mundo" (PESAVENTO, 2006, p. 7). Do mesmo modo, o texto literário, em função da coerência de sentido, apresenta, em alguns casos, "o suporte necessário para que o olhar do historiador se oriente para outras fontes e nelas consiga enxergar aquilo que ainda não viu" (PESAVENTO, 2006, p. 7), cumprindo, por isso, "um efeito multiplicador de possibilidades de leitura" (PESAVENTO, 2006, p. 7). O texto literário, acrescenta a estudiosa, (i) "revela e insinua as verdades da representação ou do simbólico através de fatos criados pela ficção" (PESAVENTO, 2006, p. 8); (ii) "é a expressão ou sintoma de formas de pensar e agir" (PESAVENTO, 2006, p. 8), sendo que os fatos ali narrados "não se apresentam como dados acontecidos, mas como possibilidades, como posturas de comportamento e sensibilidade, dotadas de credibilidade e significância" (PESAVENTO, 2006, p. 8), ou seja, "a literatura como um inegável testemunho de seu tempo" (PESAVENTO, 2006, p. 8). Em direção ao término de sua argumentação, Pesavento afirma que

a literatura é fonte de si mesma enquanto escrita de uma sensibilidade, enquanto registro, no tempo, das razões e sensibilidades dos homens em um certo momento da história. Dos seus sonhos, medos, angústias, pecados e virtudes, da regra e da contravenção, da ordem e da contramão da vida A literatura registra a vida. Literatura é, sobretudo, impressão de vida (PESAVENTO, 2006, p. 8).

Levando em conta essa caracterização da narrativa literária enquanto registro e impressão da vida, apresentada por Pesavento para defender a literatura como uma possível fonte para a história, ela nos oportuniza pensar em El señor presidente, bem como nas demais obras de Miguel Angel Asturias ${ }^{1}$, como uma forma de expressão literária da temática indianista inspirada na visão cosmológica da cultura maia e de situações específicas relacionadas ao contexto histórico local, mas de abrangência universal, e de temas comprometidos com as questões sociais. Conforme Lanoël-D’Aussenac,

1 O Prêmio Nobel de Literatura de 1967, o guatemalteco Miguel Ángel de Asturias (1899-1974), junto com Mário de Andrade, Alejo Carpentier, Jorge Luis Borges, foi um dos grandes renovadores da com Mário de Andrade, Alejo Carpentier, Jorge Luis Borges, foi un dos grandes renovadores da 'mágicorrealistas' de los 50 y 60, tan como Juan Rulfo, Jãa Guimarães Rosa g Gobión explica Gerald Martin (MARTIN, 1997, p. XXI). 
o tema tratado em El señor presidente "no es una prédica común de caráter político, sino una denuncia de alcance universal, concretada a través de la literatura de ficción, pero respaldada por un fondo de veracidad" (LANOËLD’AUSSENAC, 1997, p. 47). Nesse sentido, El señor presidente, publicado em 1946, é uma obra que denuncia a injustiça, a corrupção e a miséria, a partir da caracterização do típico ditador latino-americano, uma clara referência às sucessivas ditaduras militares que durante décadas governaram a Guatemala. Registrando a vida sem ater-se a um período e/ou acontecimento histórico específico, El señor presidente, apesar de fugir do enquadramento na categoria romance histórico, possibilita, porém, que se pense as relações ou aproximações entre a literatura e a história, como fonte uma para a outra, como sinaliza Pesavento.

Convém, contudo, antes de apresentar a análise do romance, situar seu processo de criação. El señor presidente, segundo Asturias, é um livro escrito sob a sombra do medo, um "medo ambiental" que não é apenas um elemento literário, mas, um medo nascido da alma do autor e, consequentemente, da alma humana ${ }^{2}$. Conforme o crítico Himelblau, o primeiro esboço de El señor presidente começou quando Asturias ainda era um adolescente, aluno do Colégio Del Padre Solís (HIMELBLAU, 1973). No início era apenas um conto (dez páginas) ao qual deu o nome de Los Mendigos Políticos. O processo de criação foi demorado com paradas ao longo do caminho ${ }^{3}$ que, de alguma maneira, também contribuíram para criar o fio narrativo que iria compor a obra na sua versão final.

Asturias, durante seu período como estudante de Direito, participou de algumas organizações - Associação de Estudantes Universitários, Associação

\footnotetext{
2 Declaração de Miguel Angel Asturias, ao jornal La Prensa de Managua, Nicarágua, em 19 de novembro de 1967.

3 Retomou o texto quando era aluno do curso de Direito na Guatemala (1922) e quando viajou para Paris, em 1924, voltou a trabalhar na história, concluindo-a onze anos depois, em 1933 (HIMELBLAU, 1973, p. 45).
}

de Estudantes do Direito, Tribuna do Partido Unionista (VERGARA, 2010) - sendo o representante da Guatemala no I Congreso Internacional de Estudiantes Universitarios, na Cidade do México, onde se discutia "fervorosamente as consequências da Reforma Universitaria de Córdoba (Argentina) de 1918” (VERGARA, 2010, p. 34-35). Em 1924, viajou para Paris, onde conheceu e travou amizade com Miguel de Unamuno, James Joyce e André Breton. Envolveu-se ativamente com diferentes grupos de escritores e artistas - entre eles, Pablo Picasso, Ruben Dario e Horacio Quiroga - que constituíram o "círculo de Montparnasse".

O ambiente e as circunstâncias da Paris dos anos 20, conforme o próprio Asturias, o ajudaram a encontrar o caminho e, especialmente, o sentido prático da obra que no futuro iria realizar. Foi nessa época que começou a escrever poesia e ficção, desenvolvendo um profundo interesse pela cultura maia, iniciando, junto com o mexicano J. M. Gonzáles de Mendoza, a tradução para o espanhol do Popol Vuh ${ }^{4}$, o texto sagrado dos maias. Em El señor presidente, Asturias homenageia o Popol Vuh abrindo o livro com uma epígrafe ${ }^{5}$ extraída desse texto: “... Así comenzó el secuestro de la gente que aparecia muerta en los caminos y que habia sido sacrificada ante el dios Tohil ${ }^{6}$...". Assim, devido a essa referência, Asturias substituiu o título do conto Los Mendigos políticos pelo de Tohil que mais tarde se tornaria o nome de um dos capítulos (XXXVII - El baile de Tohil) de El señor presidente.

Em 1930, ainda em Paris, onde realizou estudos de antropologia e história entre 1923-1926, publicou Leyendas de Guatemala, com o prólogo de Paul Valéry, que tratam de temas originários da tradição maia e período

${ }^{4}$ Asturias e Mendoza traduziram para o espanhol a versão francesa do Popol-Vuh realizada pelo professor francês Georges Raynaud.

5 Conforme Lanoël-d'Aussenac, essa epígrafe aparece na primeira edição em 1946, editora Costa-Amic, México, sendo mantida na primeira edição da editora Losadas, Buenos Aires, em 1948, e depois suprimida na segunda edição dessa mesma editora (LANOËL-D'AUSSENAC, 1997, p. 94).

6 Tohil, deus do fogo e da morte, objeto do culto das forças da natureza e do poder misterioso dos seres mitológicos. 
colonial, já sinalizando para a excelência artística. Retornou para Guatemala em 1933 quando, segundo Martins, já tinha terminado aquele que seria seu romance mais conhecido, "El señor presidente, la primera de las grandes novelas del continente sobre el tema de la dictadura" (MARTINS, 1997, p. XXII), que não pode ser publicada, pois havia se instalado em seu país um governo de repressão chefiado por outro tirano, Jorge Ubico (1931-1944).

Em 1945, o então presidente Juan José Arévalo, amigo de Asturias da época parisiense, o nomeou como embaixador, primeiro no México, em 1946, onde, nesse mesmo ano, publicou de El señor presidente, e depois na Argentina, quando em 1948, voltou a publicar El señor presidente, agora pela Editorial Losada S.A. Com o início do governo do Coronel Carlos Castillo Armas, em 1954, exilou-se da Guatemala. Sua reabilitação só ocorreu em 1966 quando o presidente eleito Julio César Méndez Montenegro chegou ao poder. Nesse ano, em 1966, lhe foi devolvida a cidadania guatemalteca, tornouse embaixador na França e recebeu o Prêmio Lenin da Paz pelo conteúdo fortemente anti-imperialista de seus poemas e romances. Um ano depois ganhou o Nobel de Literatura por "sus coloridos escritos profundamente arraigados en la individualidad nacional y en las tradiciones indígenas de América"7. Asturias viveu seus últimos anos em Madrid, onde morreu em 1974, sendo enterrado no cemitério Père Lachaise, em Paris.

Para Sartre, "a função do escritor é fazer com que ninguém possa ignorar o mundo e considerar-se inocente diante dele" (SARTRE, 2004, p. 21). Nesse sentido, El señor presidente é a representação clara e dolorosa da destruição moral que um regime baseado no terror pode provocar. É, portanto, um livro comprometido e, como tal, localiza o leitor no sentido histórico e social de seu conteúdo. Nas quatro partes que o compõem, o leitor se deparará com

\footnotetext{
Disponível em: <http://www.fondodeculturaeconomica.com/Editorial/Prensa/Detalle.aspx?seccion= Detalle\&id_desplegado=38334>. Acesso em: 6 jul. 2015.
}

uma trama na qual predominam o medo e a crueldade, um espaço onde "um grito de dor é sinal da dor que provoca" (SARTRE, 2004, p. 11).

Para revelar esse mundo que não pode ser ignorado, El señor presidente dialoga com as tradições culturais americanas anteriores à colonização, trazendo à vida o mito de Tohil na figura diabólica do ditador, cuja reconfiguração não só o enriquece, mas também possibilita um alargamento dos horizontes do que se costuma denominar imaginário popular. Além disso, pelas características da obra, pode-se dizer que ela se encontra na fronteira entre o que se chama romance histórico tradicional e o "novo romance histórico" ou fora desse enquadramento, ficando apenas como um "registro ou impressão da vida" (PESAVENTO, 2006, p. 6). Do primeiro ela herdou a busca por uma identidade nacional, dessa vez centrada nos problemas contemporâneos como a luta entre a civilização urbana e a barbárie rural, a exploração socioeconômica e o racismo (MENTON, 1993); enquanto que da segunda, encontra-se a distorção consciente da história, mediante anacronismos, omissões e exageros e a presença de fenômenos que, mais tarde, seriam estudados por Bakhtin como a carnavalização, a paródia e heteroglossia (MENTON, 1993). Elementos desse segundo gênero também podem ser percebidos na "polifonia de estilos e modalidades baseada, especialmente, na fragmentação dos signos de identidades nacionais, realizada a partir da desconstrução dos valores tradicionais" (ESTEVES, 2010, p. 36).

Entre as personagens marcantes dessa obra hibrida, porque ficcionaliza a história ou porque, como afirma Lanoël-d'Aussenac (1997, p. 66), "incorpora la historia a la novela y no a la inversa” (LANOËL-D’AUSSENAC, 1997, p. 66) encontram-se duas mulheres unidas pela tragédia, que terão de fazer frente a esse jogo de poder entre o bem e o mal: a filha de um general que caiu em desgraça, Camila Canales, e a mulher do povo, presa em uma armadilha política, Niña Fedina. Na trajetória dessas personagens se revela uma narrativa que 
coloca à mostra a luta travada entre as forças da luz - o povo oprimido do qual fazem parte as mulheres, muitas vezes ignoradas - e a das trevas - o ditador e todos que, por medo ou ambição, compactuam com ele. Uma dualidade que está presente nos mitos latino-americanos e que é a chave para compreender o sentido social e as razões subjetivas presentes na gênese de El señor presidente. Portanto, ao destacar essas duas personagens, objetiva-se mostrar, como sinalizou Pesavento, que a literatura e a história "guardam com a realidade distintos níveis de aproximação" (PESAVENTO, 2006, p. 7), e que a literatura pode servir de fonte para a história porque é um "inegável registro de seu tempo" (PESAVENTO, 2006, p. 8). A trajetória de Camila Canales e Niña Fédina, relatada por Asturias, contribui para a verossimilhança narrativa, levando em conta que ela se localiza em um espaço não denominado, mas que "resulta fácil deducir que se trata de Guatemala, aunque, sin menoscabo de la esencia argumental, podría tratarse de cualquier otro país de América Latina" (LANOËL-D’AUSSENAC, 1997, p. 56), pois,

los acontecimientos y las circunstancias que generaron el motivo del texto, es decir, la tiranía, las profundas injusticias sociales, la explotación abusiva de los recursos propios de una nación por empresas extranjeras, la violencia y la corrupción de los gobiernos, son componentes de un complejo sistema social común en casi todos los países de América Latina (LANOËL-D’AUSSENAC, 1997, p. 80).

Pensando nessa representação dos acontecimentos e das circunstâncias, convém recorrer a Antonio Candido e sua pergunta sobre a possibilidade de copiar "no romance um ser vivo e, assim, aproveitar integralmente a sua realidade" (CANDIDO, 2014, p. 65, grifo do autor). A resposta é que "em sentido absoluto" isso não é possível porque "não há como captar a totalidade do modo de ser duma pessoa, ou sequer conhecê-la" (CANDIDO, 2014, p. 65). Contrário a essa posição, Orhan Pamuk, Prêmio Nobel de Literatura de 2006, acredita que "o romance conta com nossa memória de experiências comuns da vida e de impressões sensoriais que às vezes nem sequer percebemos" (PAMUK, 2011, p. 69). Essas duas posições, mesmo que opostas, são significativas para a reflexão acerca da aproximação da literatura e da história enquanto "narrativas que tem o real como referente, para confirmá-lo ou negá-lo, construindo sobre ele toda uma outra versão, ou ainda para ultrapassá-lo. Como narrativas, são representações que se referem à vida e que a explicam" (PESAVENTO, 2006, p. 3).

Assim, mesmo que "em sentido absoluto" seja impossível aproveitar integralmente a realidade, no caso caracterizar um ser humano como "ele realmente é”, é também impossível não pensar o quanto da experiência pessoal do autor está presente na narrativa que ele construiu. Sobre isso, pode-se inferir que a mãe de Asturias, "doña" María Rosales, influenciou profundamente seu trabalho como escritor porque era ela que o estimulava a prosseguir quando começou a escrever suas primeiras produções poéticas, foi ela quem financiou a publicação da primeira edição de El señor presidente, e a ela Asturias dedicou seu primeiro livro Leyendas de Guatemala: "A mi madre, que me contaba cuentos" (ASTURIAS, 2011, p. 5). Logo, nada mais natural do que a figura materna encontrar papel de destaque na construção de El señor presidente, como uma "expressão do registro e impressão da vida" (PESAVENTO, 2006, p. 8).

Por isso, as diferentes imagens da mãe que aparecem no enredo umas sublimes e outras patéticas - adquirem um significado especial na obra e constituem um elemento uniforme e constante do aspecto humano de sua literatura. "La Chabelona", empregada na casa dos Canales, mulher que cuidou de Camila desde bebê, é uma dessas figuras maternais que, mesmo sendo uma personagem secundária, deixa uma marca indelével na história, impressionando pela força dramática e pela empatia que é capaz de despertar. A dor pela perda daquela que considerava como filha é representada de forma tão brutal que seus gritos de agonia parecem 
sair "de los espejos rotos, de los cristales hechos trizas, de las sillas maltrechas, de las cómodas forzadas, de los retratos caídos" (ASTURIAS, 1997, p. 199). A construção dessas imagens obedece a um plano onde o caos de uma casa violada, mistura-se ao sofrimento de uma mulher que perdeu tudo em meio a uma selvageria sem sentido. A destruição física do ambiente reflete a deterioração, em ritmo exponencial, da mente de "Chabelona".

Desde o início a história de Niña - como de tantas outras mulheres antes e depois dela - está marcada pela tragédia. Na tentativa de ajudar Camila, acaba sendo acusada de ser cúmplice na fuga do general Canales, pai de Camila. Mesmo alegando inocência é levada à prisão e enquanto os soldados a maltratam, apenas uma mulher sem nome, também do povo, atreve-se a defendê-la diante de seus captores: “Calzonudos!... Para lo que les sirven las armas!... Deberían tener más vergüenza! - intervino una mujer que volvía del mercado con el canasto lleno de verduras y frutas" (ASTURIAS, 1997, p. 204). Como explica Candido, "a natureza da personagem depende em parte da concepção que preside o romance e das intenções do romancista" (CANDIDO, 2014, p. 74). Nada mais significativo do que uma mulher defendendo outra mulher, indivíduos "naturalmente" excluídos e maltratados em um regime patriarcal e despótico. Asturias talvez pensasse que somente uma mulher poderia compreender a humilhação de ser agredida em plena luz do dia diante dos "transeuntes que la miraban asustados" (ASTURIAS, 1997, p. 204).

No entanto, firme em sua intenção de mostrar o horror que existe por debaixo do silêncio e da omissão, a trajetória de Niña Felina não se encerra na sua caminhada, pelas ruas da cidade imaginada por Asturias, até a prisão. No capítulo XVI, En la Casa Nueva, o autor descreve o inferno que Niña irá suportar, mostrando como a dor da humilhação pública é substituída pelo horror da tortura:
La primera noche en un calabozo es algo terrible. El prisionero se va quedando en la sombra como fuera de la vida, en un mundo de pesadilla. Los muros desaparecen, se borra el techo, se pierde el piso, y, sin embargo, ¡qué lejos el anima de sentirse libre!; más bien se siente muerta (ASTURIAS, 1997, p. 220).

Niña, assim como todas as prisioneiras na Casa Nueva, está à mercê de seus torturadores, ela representa, numa perspectiva metafórica, os abusos, as violências e as privações as quais estão sujeitas todas as classes sociais menos favorecidas, deixando claro que o mal sempre pode atingir níveis que muitas vezes não somos capazes de entender. A forma como Asturias constrói a personagem Niña permite que o leitor se identifique com o sofrimento e a dor da prisão, do suplício que a morte de uma criança inocente pode provocar. Niña incorpora ainda todas as mães que nas inúmeras ditaduras que governaram a América Latina perderam seus filhos nas mãos dos torturadores. Asturias escolhe e distribui de tal forma os traços dessa mãe impotente e desesperada que é impossível permanecer alheio ao seu sofrimento: “ $¡ A y$, mi hijo se me muere! ¡Ay, mi hijo se muere! ¡Ay, mi vida, mi pedacito, mi vida!... ¡Vengan, por Dios! ¡Abran! ¡Por Dios, abran! ¡Se me muere mi hijo! ¡Virgen Santísima! ¡San Antonio bendito! ¡Jesús de Santa Catarina!” (ASTURIAS, 1997, p. 228).

Asturias ao criar Niña, uma mulher do povo como tantas outras, deu voz a todos aqueles que também sofreram nas mãos de regimes totalitários e não puderam gritar e nem reagir contra a opressão e a intolerância dos quais foram vítimas. El señor presidente não é, portanto, apenas um discurso comum de caráter político, mas uma denúncia de caráter universal. Asturias cria "seu próprio universo sem se sujeitar nem ao pacto da veracidade, que impõe o discurso histórico, nem ao pacto da verossimilhança, que mantinha, de certa forma, o discurso ficcional mais tradicional" (ESTEVES, 2010, p. 34). Ele pode não ter pego em armas como sugeriu Sartre, mas com Niña Fedina 
demonstrou seu compromisso social e político com a verdade histórica, pois os abusos e a tirania institucionalizada, infelizmente, continuam sendo temas que nunca perdem a validade.

Nesse universo repressivo, um dos principais argumentos de El señor presidente é o amor entre Camila Canales e Miguel "Cara de Ángel", que se constrói ao sabor dos interesses e das intrigas que pouco tem a ver com os verdadeiros desejos desses dois personagens. No início da história, Camila é uma moça respeitável e educada, mas, ao contrário do que se esperaria de um membro de uma classe social mais abastada, é uma jovem simples, sempre pronta a ajudar os mais necessitados. No entanto, uma reviravolta na vida dessa "moça de família" a coloca frente a frente com a maldade explícita de um governante despótico e perverso: a prisão do pai acusado por crime de traição.

A experiência de Camila é construída de forma a não ficar dúvidas de que ela, assim como Niña Fedina, é mais uma vítima de um regime baseado na opressão e no medo. Asturias faz o leitor seguir a trajetória de Camila, desde a fuga de sua casa, passando pela rejeição de seus parentes, até o momento que encontra um pouco de tranquilidade e amor justamente em Miguel "Cara de Ángel”, o homem de confiança do Presidente. A personalidade de Camila, antes estável, vai sendo desconstruída para depois ser reconstruída a partir das experiências traumáticas das quais foi vítima. O personagem cresce ao longo da narrativa, deixa de ser uma jovem inocente para se transformar no final da trama em uma mulher calejada pela dor e a desilusão.

Bakhtin, comentando sobre valores e momentos da vida em relação ao amor, afirma:

Se os valores heróicos determinam os momentos fundamentais e os acontecimentos da vida privado-social, privado-cultural e privado-histórica (a gesta) - a orientação volitiva básica na vida -, o amor determina-lhes a tensão emocional na medida em que pensa e condensa os detalhes internos e externos dessa vida (BAKHTIN, 1997, p. 171, grifo do autor).
Em El señor presidente, essa “tensão emocional”, causada pelo sentimento amoroso, se mantém desde o momento em que Camila conhece Miguel até o fim, quando, enganada pelas artimanhas do ditador, esquecida pela família e envelhecida pelo sofrimento, decide seguir em frente, deixando a cidade com o filho nos braços. Para Asturias, o campo é a antítese da cidade, pois enquanto o segundo representa o mal, a tirania e a traição, o primeiro é o símbolo do bem, da pureza e da verdadeira nobreza. Essa dualidade explorada pelo autor ao longo de toda a obra, fica evidente no parágrafo no qual descreve não só o lugar onde Camila decide criar o filho, mas também o sentimento que esse novo ambiente desperta nela:

Las ovejas se entretenían en lamer las crías. ¡Qué sensación tan completa de bienestar de domingo daba aquel ir y venir de la lengua materna por el cuerpo del recental, que entremoría los ojos pestañosos al sentir la caricia! Los potrancos correteaban en pos de las yeguas de mirada húmeda. Los terneros mugían con las fauces babeantes de dicha junto a las ubres llenas. Sin saber por qué, como si la vida renaciera en ella, al concluir el repique del bautizo, apretó a su hijo contra su corazón (ASTURIAS, 1997, p. 394).

A técnica narrativa de Asturias recorre frequentemente à associação de ideias para expressar o sentido completo de certas paisagens ou conceitos. Assim, a sensação de renascer sentida por Camila pode ser interpretada como uma volta a uma época de inocência quando a crueldade imposta por um governante (ou regime) perverso ainda não era conhecida. Na frase final do capítulo Gallina ciega isso fica ainda mais claro, pois, o narrador declara que "El pequeño Miguel" crescerá no campo e se tornará um "hombre de campo" (ASTURIAS, 1997, p. 394), portanto, alguém com valores distintos daqueles que ficaram para trás na cidade. Esse narrador é também um personagem que, mesmo sendo incorpóreo, pode-se inferir que representa a exteriorização do sentimento de Asturias. 
Para Pamuk, "o romancista desenvolve seus heróis de acordo com os tópicos que quer pesquisar, explorar e expor e com as experiências de vida que deseja pôr sob o foco de sua imaginação e sua criatividade" (PAMUK, 2011, p. 59). No caso de Asturias, apesar de muitas vezes suas mensagens terem um duplo sentido, elas permitem o vislumbre de uma realidade brutal que supera qualquer tipo de fantasia. Sua narrativa tem um eixo estrutural que gira em torno da dicotomia "vida-morte", existindo um forte predomínio do elemento "morte" sobre os fatores "vida-ilusão-esperança".

Nesse sentido, é perceptível o amadurecimento pelo qual passa Camila ao longo da narrativa. Ela inicia como uma jovem pura, intocada pelo mal, para terminar como uma mulher curtida pelo sofrimento, rejeitando tudo o que a ligava a sua antiga vida e escolhendo viver no campo, longe da barbárie representada pela cidade e seu ditador. Assim, na figura de Camila mais um crime pôde ser imputado ao tirano: a morte da inocência. No entanto, talvez para deixar algum espaço para a esperança e, consequentemente, para a vida, Asturias permitiu que Camila renascesse para se tornar a mulher forte que iremos encontrar no final do capítulo Gallina ciega.

Outro aspecto que merece destaque na obra asturiana é a presença dos mitos latino-americanos mesmo que, muitas vezes, eles não apareçam de forma explícita. A própria imagem do Presidente baseada no mito de Tohil, o deus do fogo e da morte, demonstra que Asturias, ao criar esse personagem, quis dar a ele as mesmas características dessa figura mitológica. Desse modo, misturada a caricatura que construiu do típico ditador latino-americano, vamos encontrar a representação da figura universal do tirano, capaz de crueldades inomináveis contra seres inocentes e indefesos.

Entre esses seres inocentes e indefesos estão as mulheres de El señor presidente. Conhecedor do tipo de sociedade - patriarcal e machista - que predominava (e em muitos lugares ainda predomina) na América Latina, Asturias criou e desenvolveu duas personagens femininas que, inseridas nesse contexto, refletem, junto com o autor, "um mesmo mundo onde os valores genealógicos conservam toda a sua importância" (BAKHTIN, 1997, p. 192). Para dar consistência à sua narrativa, enriquecendo-a a partir de detalhes colhidos da realidade que ele mesmo testemunhou, preocupou-se em apresentar duas mulheres que, apesar de terem vindo de camadas sociais distintas, experimentaram os mesmos sentimentos de impotência diante dos abusos cometidos pelo cruel tirano representado pelo Presidente. Tal escolha, ou seja, partir da realidade, aproxima-se, como já mencionado, da história, porque "literatura e história são narrativas que tem o real como referente para confirmá-lo ou negá-lo” (PESAVENTO, 2006, p. 3). Neste caso, a literatura serve como confirmação do real, pois a tirania retratada, mesmo que não tenha ocorrido tal qual, é verídica.

Sobre o processo de criação das personagens, para Candido, a caracterização de um personagem depende de "uma escolha e distribuição conveniente de traços limitados e expressivos, que se entrosem na composição geral e sugiram a totalidade dum modo-de-ser duma existência" (CANDIDO, 2014, p. 75). Para Pamuk, primeiro surge a vontade de explorar determinados tópicos e que "só depois o romancista concebe as figuras mais adequadas para elucidar tais tópicos" (PAMUK, 2011, p. 59). Analisando as duas ideias é possível perceber que elas não se excluem, ao contrário, se complementam, pelo menos no que se refere a El señor presidente, cujos fatos narrados na trama não aconteceram dessa forma na história, mas existem de fato para a voz narrativa ali utilizada.

Em função disso, ou seja, dessas escolhas, pode-se afirmar que a narrativa criada por Asturias traz a público as terríveis crueldades sofridas por homens e mulheres em um país latino-americano sob a ditadura de um governo totalitário. Assim, para dar forma a essa história foi preciso criar personagens que, a partir de "traços limitados e expressivos", trouxessem "vida" à trama criada pelo autor (CANDIDO, 2014, p. 75). Uma "vida" 
ficcional que em tudo se assemelha à vida real, mas que é capaz de nos dar um "conhecimento mais completo, mais coerente do que o conhecimento decepcionante e fragmentário dos seres” (CANDIDO, 2014, p. 64), com certeza, uma das principais marcas da ficção.

Em seu discurso à Academia Sueca quando recebeu o Prêmio Nobel de Literatura, em 1967, Miguel Ángel Asturias declarou:

Palabra y lenguaje harán participar al lector en la vida de nuestras creaciones. Inquietar, desasosegar, obtener la adhesión del lector, el cual olvidándose de su cotidiano vivir, entrará a compartir el juego, las situaciones y personajes, en una novelística que mantiene intactos sus valores humanos. Nada se usa para disvirtuar al hombre, sino para completarlo y esto es tal vez lo que conquista y perturba en ella, lo que transforma nuestra novela en vehículo de ideas, en intérprete de pueblos usando como instrumento un lenguaje con dimensión literaria, con valor mágico imponderable y con profunda proyección humana. ${ }^{8}$

Assim, quando Asturias representa a dor de uma mãe que vê seu filho morrer de fome sabendo que há leite em seu seio para alimentá-lo, grava-se na mente do leitor uma imagem tão crua e terrível que, esse mesmo leitor é capaz de ouvir seus gritos de agonia, compartilhando uma experiência que transcende a ficção. Do mesmo modo, mas em outro nível, quando ele retrata o sofrimento prolongado pelo amor que partiu e não mais voltou, o leitor começa a desejar que a morte caia sobre a personagem para assim acabar com a sua aflição. Por essa razão, tentar rotular sua narrativa como "romance tradicional" ou "novo romance histórico", deixa de ter relevância, pois o objetivo da ficção deve ser o de superar o descontentamento que a realidade causa, assim como

\footnotetext{
${ }^{8}$ Disponível em: <http://www.nobelprize.org/nobel_prizes/literature/laureates/1967/asturiaslecture-sp.html>. Acesso em: 07 jul. 2015.
}

enriquecer e completar a existência; compensar o ser humano de sua trágica condição, a de desejar e sonhar com o que não pode realmente atingir. Assim, os romances não são escritos para contar a vida, mas para transformá-la após o processo de leitura (ESTEVES, 2010, p. 43).

Pode-se, ainda, seguindo Pesavento, afirmar que o romance de Asturias, sem ser romance histórico, serve como fonte para a história porque "dá a ver, mesmo que de forma cifrada, as imagens sensíveis do mundo" (PESAVENTO, 2006, p. 7), porque oportuniza "um inegável testemunho de seu tempo" (PESAVENTO, 2006, p. 8), como registro e impressão da vida. Niña e Camila são duas criações de Asturias que, em El señor presidente, cumprem o propósito, por ele explicitado, de inquietar e perturbar o leitor, provocando sua imediata adesão a uma obra que é considerada uma das mais importantes da literatura latino-americana e a primeira grande novela do continente latino-americano a abordar o tema da ditadura.

\section{Referências}

ASTURIAS, Miguel Àngel. El señor presidente. Madrid: Cátedra, 1997.

ASTURIAS, Miguel Àngel. Leyendas de Guatemala. Madrid: Alianza Editorial, 2011.

BAKHTIN, Mikhail. Estética da criação verbal. Tradução feita a partir do francês por Maria Ermantina Galvão G. Pereira; revisão da tradução de Marina Appenzeller. São Paulo: Martins Fontes, 1997.

CANDIDO, Antonio et al. A personagem de ficção. 13. ed. São Paulo: Perspectiva, 2014.

ESTEVES, Antonio R. O romance histórico brasileiro contemporâneo (1975-2000). São Paulo: UNESP, 2010.

HIMELBLAU, Jack. El señor presidente: Antecedents, Sources, and Reality. Hispanic Review, v. 41, n. 1, p. 43-78, 1973.

MARTIN, Gerald. Introducción del Coordinador. In: ASTURIAS, Miguel Ángel. Hombres de maíz. Edición crítica. Madrid; Paris; México; Buenos Aires; São Paulo; Lima; Guatemala; San José de Costa Rica; Santiago de Chile: ALLCA XX, 1997. 
MENTON, Seymour. La nueva novela histórica de la América Latina (1979-1992). México: Fondo de Cultura Económica, 1993.

LANOËL-D’AUSSENAC, Alejandro (Ed.). Introducción. In: ASTURIAS, Miguel Angel. El señor presidente. Madrid, 1997. p. 9-110.

PAMUK, Orhan. O romancista ingênuo e o sentimental. Tradução de Hildegard Feist. São Paulo: Companhia das Letras, 2011.

PESAVENTO, Sandra Jatahy. História \& Literatura: uma velha-nova história. Nuevo Mundo Mundos Nuevos, Debates, 2006. Em linha em 28/01/2006. Disponível em: <http:// nuevomundo.revues.org/1560>. Acesso em: 02 out. 2015.

SARTRE, Jean-Paul. $O$ que é literatura? Tradução de Carlos Felipe Moisés. São Paulo: Ática, 2004.

VERGARA, Amina Maria Figueroa. A United Fruit Company e a Guatemala de Miguel Angel Asturias, f. 142. Dissertação (Mestrado em História Social) - Universidade de São Paulo. São Paulo, 2010. Disponível em: <http://www.teses.usp.br/teses/disponiveis/8/8138/ tde-30042010-132256/pt-br.php>. Acesso em: 14 set. 2015.

Recebido em: 10/01/2016.

Aprovado em: 01/05/2016. 